\title{
Mechanical properties of very thin cover slip glass disk
}

\author{
A SEAL, A K DALUi, M BANERJEe, A K MUKHOPADHYAY* and K K PHANI \\ Central Glass and Ceramic Research Institute, Kolkata 700 032, India
}

\begin{abstract}
The biaxial flexural strength, Young's modulus, Vicker's microhardness and fracture toughness data for very thin, commercial, soda-lime-silica cover slip glass (diameter, D-18 mm, thickness, T-0.3 mm; T/D $\approx 0.02$ ) are reported here. The ball on ring biaxial flexure tests were conducted at room temperature as a function of the support ring diameter $(\approx 10-20 \mathrm{~mm})$ and cross head speed $\left(0 \cdot 1-10 \mathrm{~mm} \mathrm{~min}^{-1}\right)$. In addition, the Weibull modulus data were also determined. The Young's modulus data was measured using a linear variable differential transformer (LVDT) from biaxial flexure tests and was checked out to be comparable to the data obtained independently from the ultrasonic time of flight measurement using a $15 \mathrm{MHz}$ transducer. The microhardness data was obtained for the applied load range of 0-1-20 N. The fracture toughness $\left(K_{\mathrm{IC}}\right)$ data was obtained by the indentation technique at an applied load of $20 \mathrm{~N}$.
\end{abstract}

Keywords. Biaxial flexural strength; Young's modulus; fracture toughness; Weibull modulus.

\section{Introduction}

The strength of the brittle materials is determined mostly by their surface conditions. Glass being a brittle material is prone to fail from the surface flaws. To evaluate the strength of such materials the conventional 3-point and 4-point bend tests are normally used. But, these to some extent are inadequate because there is always a chance of machine induced edge flaws interfering with the data. The strength value thus obtained are lower than the actual strength of the material. To avoid the presence of such spurious influence on the measured data, there is a great deal of current interest in the biaxial flexural strength test. In biaxial flexure test the specimen is loaded on opposite sides with radially symmetrical bending forces. Under such loading condition the maximum tensile stress occurs at the central loading zone rather than at the edges. As a result, the cracks initiate at the centre of the disk and move toward the edges. This helps to eliminate or, at least, minimize the edge effect on the strength data. Also, a comparatively greater surface area is exposed to maximum stress. Further, in the biaxial tests, the stress state is more severe in nature that makes it suitable for conservative design in terms of complicated stress application.

Various modifications of biaxial flexural test have been adopted to a variety of brittle materials including glass (McKiney and Herbert 1970; Marshall 1980; Shetty et al 1980, 1983; DeWith and Wageman 1989; Hulm et al 1998). These include ring on ring (Marshall 1980; Hulm et al 1998), ball on ring (McKiney and Herbert 1970; DeWith and Wageman 1989), uniform pressure on disk (Shetty et al 1983) and piston on three balls (Shetty et al 1980) tests. The samples used were mostly bulk glass

\footnotetext{
*Author for correspondence
}

(Marshall 1980; DeWith and Wageman 1989), glassceramics (Shetty et al 1980) and structural ceramics such as alumina, ZTA and $3 \mathrm{~mol} \%$ yttria stabilized TZP (McKiney and Herbert 1970; Shetty et al 1983; Hulm et al 1998). Interestingly, all these investigations employ typically disk shaped specimens with a thickness to diameter ratio (T/D) ranging from 0·03-0.08. However, the biaxial flexural strength and other mechanical properties such as Young's modulus, hardness and fracture toughness of very thin glass disks have been rarely studied in detail (Folsom et al 1994). Therefore, the objective of the present work was to determine the mechanical properties of a very thin $(0.3 \mathrm{~mm})$ glass disk having a T/D ratio of as low as $0 \cdot 017$.

\section{Experimental}

Soda lime silica cover slip glass disk of diameter $18 \mathrm{~mm}$ and thickness $0.3 \mathrm{~mm}$ was commercially procured (Grade: Dr Watts, India) for the study. All tests were conducted on as received samples. The mechanical strength $(\sigma)$ of the glass cover slip was evaluated at $30^{\circ} \mathrm{C}$ in biaxial flexure, with a ball on ring arrangement (DeWith and Wageman 1989) as a function of cross head speed $(0 \cdot 1-10 \mathrm{~mm} / \mathrm{min})$ and support ring diameter $(\approx 9-17 \mathrm{~mm})$. A universal testing machine [Instron 5500R] was used for this purpose. The displacement at failure $(d)$ was measured with a linear variable differential transformer (LVDT). Sensivity of the LVDT was $\approx 0.7 \%$ of the full scale deflection.

The Weibull modulus $(m)$ was calculated from the strength data obtained by biaxial flexure test conducted on the glass disks with three different support ring diameters of $9.14 \mathrm{~mm}, 15.11 \mathrm{~mm}$ and $17.09 \mathrm{~mm}$. For each support ring diameter, at least fifty glass disks were tested and the 
fracture stress $(\sigma)$ was calculated following the method of DeWith and Wageman (1989). The Weibull modulus was determined from the slope of $\left[\ln \left\{\ln \left\{1 /\left(1-P_{\mathrm{s}}\right)\right\}\right\}\right]$ vs $[\ln (\sigma)]$ plot. Here, $P_{\mathrm{s}}$ is the failure probability, defined by the relation

$$
P_{\mathrm{s}}=[(I-0 \cdot 5) / N]
$$

where $I$ is the ranking number of a specimen in a sample of size $(N)$ classified in increasing order of fracture stress $(\sigma)$.

The Young's modulus $(E)$ of the glass disks was measured from the displacement $(d)$ at fracture, following the procedure of DeWith and Wageman (1989). The $(d)$ values were measured by LVDT as mentioned earlier. This Young's modulus data was compared with the

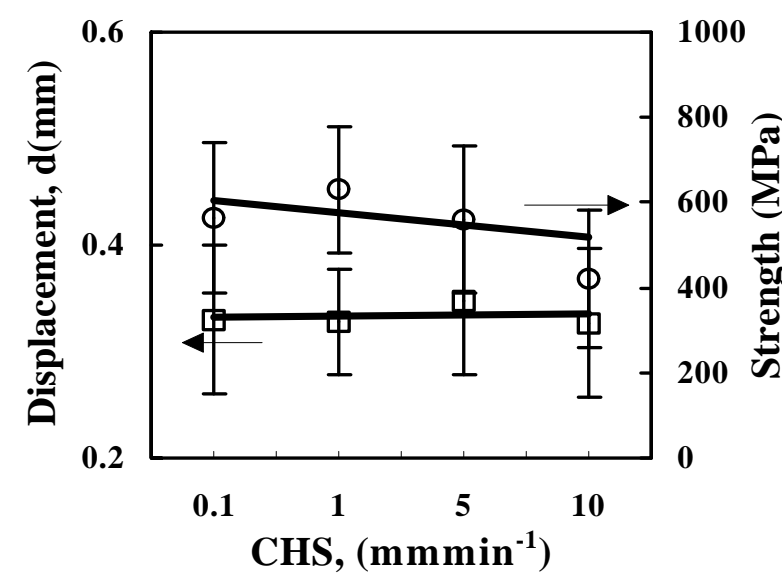

Figure 1. Mechanical strength $(\sigma)$ and load point displacement $(d)$ of glass cover slip as a function of cross head speed in biaxial test.

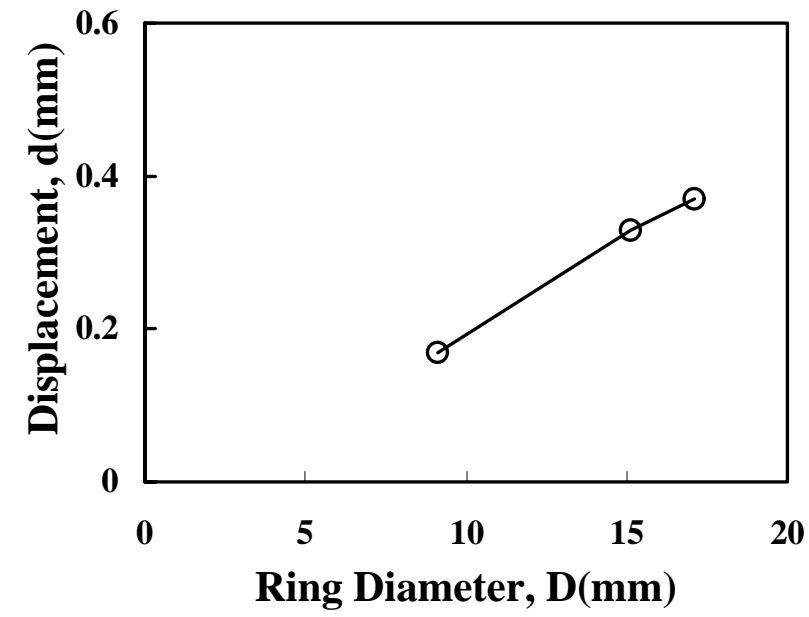

Figure 2. Load point displacement $(d)$ of glass cover slip as a function of the support ring diameter used in biaxial flexure test.
$E$-value measured by the ultrasonic time of flight technique (Martin and Rosen 1987). For this purpose a $15 \mathrm{MHz}$ transducer (OLF-4K08128) and a suitable couplant (ULTRAGEL II, Echo Ultrasound, USA) were used. Each reported data is an average of at least fifty samples.

The Vicker's microhardness $\left(H_{\mathrm{V}}\right)$ and fracture toughness data were obtained on polished samples. The surface roughness (CLA) of the polished samples was typically about $0.31 \mu \mathrm{m}$. The microhardness data was obtained with a Vicker's square pyramidal indenter fitted in a conventional hardness tester (Shimadzu HMV-2000) and using an applied load range of 0.1-20 N. Similarly, the indentation fracture toughness value $\left(K_{\mathrm{IC}}\right)$ was measured using the same machine at an applied load of $20 \mathrm{~N}$, following the procedure of Anstis et al (1981).

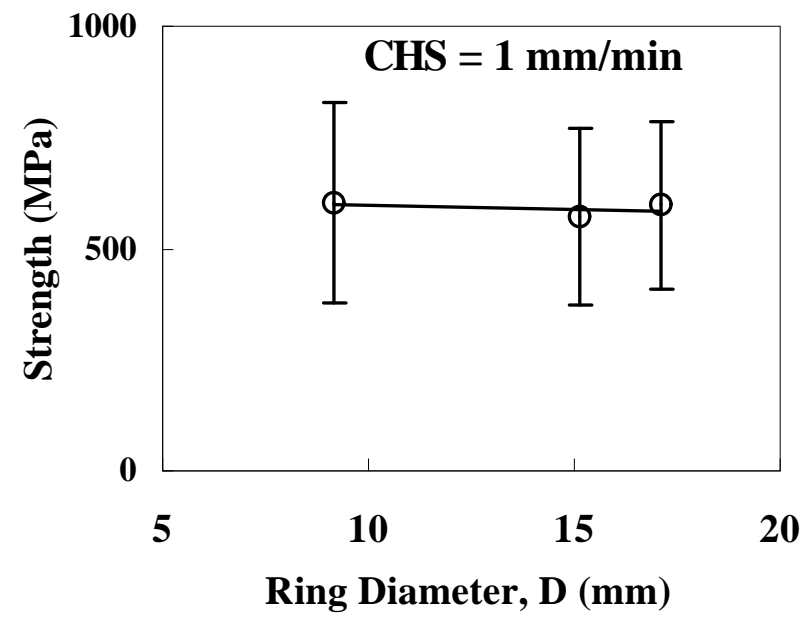

Figure 3. Mechanical strength $(\sigma)$ of glass cover slip as a function of the support ring diameter.

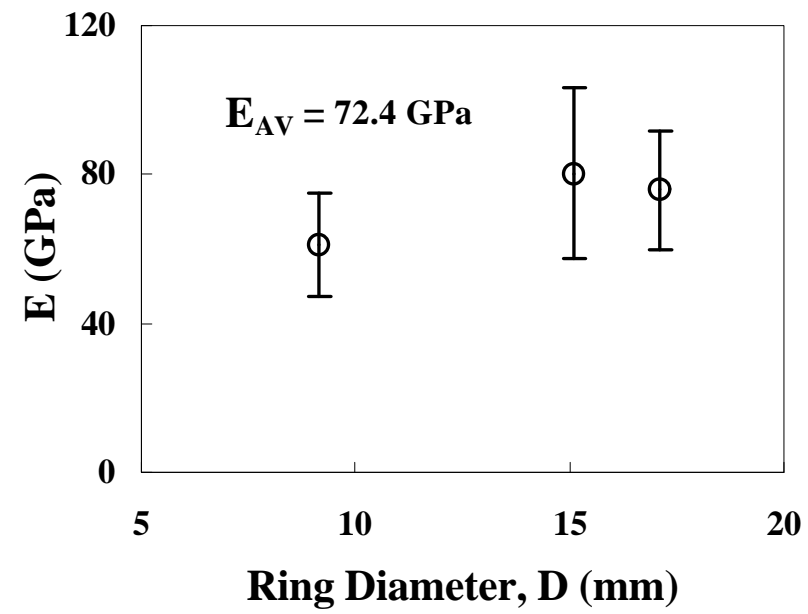

Figure 4. Young's modulus $(E)$ of glass cover slip obtained by biaxial flexure test as a function of the support ring diameter. 


\section{Results}

The results from the various biaxial flexural strength tests are presented in figures 1-4. The typical scatter in the data is represented by error bars which stand for \pm 1 standard deviation. The fracture stress $(\sigma)$ of the thin glass disks decreased very slightly and the displacement at fracture $(d)$ was insensitive with the range of cross head speeds investigated in the present work (figure 1). The displacement at fracture, however, increased with increasing support ring diameter (figure 2). For a given cross head speed $(1 \mathrm{~mm} / \mathrm{min})$, the strength $(\sigma)$ of the glass disks was also insensitive to the variations in the support ring diameter $\approx 9-17 \mathrm{~mm}$ (figure 3 ).

The Young's modulus $(E)$ data obtained from the LVDT measurement are shown in figure 4. Clearly, the data were insensitive to the variations in the support ring diameter. Thus, the average $E$-value was $72.4 \mathrm{GPa}$ for the present thin glass disks (figure 4). Similarly, the Young's modulus $(E)$ data obtained from the ultrasonic time of flight measurement technique are shown in figure 5 as a function of the average thickness $(0 \cdot 29-0.35 \mathrm{~mm})$ of glass disks. As expected, the data did not show any significant sensitivity towards the thickness of the glass disks. Further, the average $E$-value was $84.9 \mathrm{GPa}$. This data was comparable to the value of $72.4 \mathrm{GPa}$ obtained by the LVDT measurement (figure 4). However, the ultrasonic time of flight measurement technique gave a slightly higher value. The reason for this is yet to be known but could be linked to incorrect assessment of the time of flight due to the presence of strong interference between the incident and reflected waveforms from the very thin cross section of the present glass disks (T/D-0.017). On the other hand, the $E$-value obtained by the LVDT

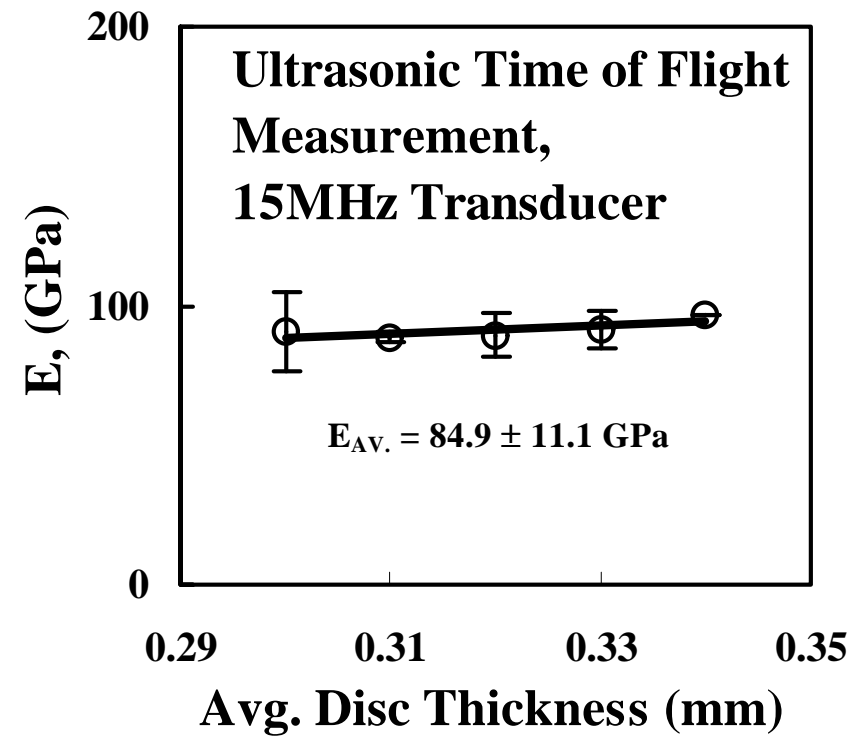

Figure 5. Young's modulus $(E)$ data of glass cover slip obtained by the ultrasonic time of flight measurement technique. measurement technique, matched very closely with the literature data on bulk soda lime silica glass disk of diameter $60 \mathrm{~mm}$ and thickness $2.12 \mathrm{~mm}$ [cf. $72.5 \mathrm{GPa}$ (DeWith and Wageman 1989)] vs $72.4 \mathrm{GPa}$ [present work].

Based on the results of the biaxial flexural strength tests conducted on the thin glass disks, the calculated values of the Weibull moduli $(m)$ were $2.77,3.09$ and 3.83 for the support ring diameters of $9.14 \mathrm{~mm}, 15.11 \mathrm{~mm}$ and $17.09 \mathrm{~mm}$, respectively (figure 6). This result indicated that within the range of variations in support ring diameter employed in the present work, the intrinsic strength of the very thin glass disks were almost unaffected as reflected also in the data (figure 3 ).

The scanning electron microscope (SEM) observation of typical fracture surface (figure 7) confirmed that the

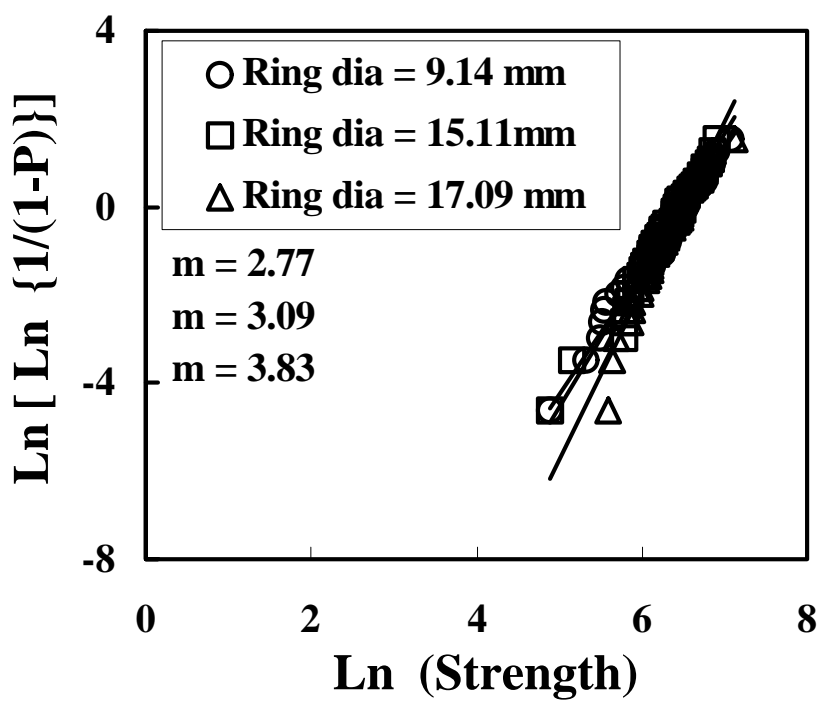

Figure 6. Fracture statistics of glass cover slip as a function of support ring diameter of $9.14 \mathrm{~mm}, 15.11 \mathrm{~mm}$ and $17.09 \mathrm{~mm}$ in biaxial flexure test.

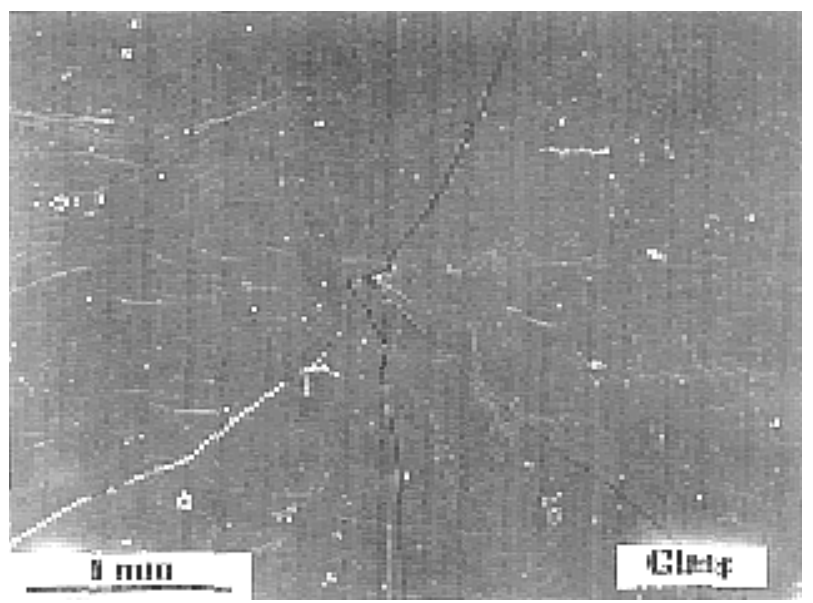

Figure 7. Typical fracture surface obtained from biaxial flexure test of the thin glass disks. 


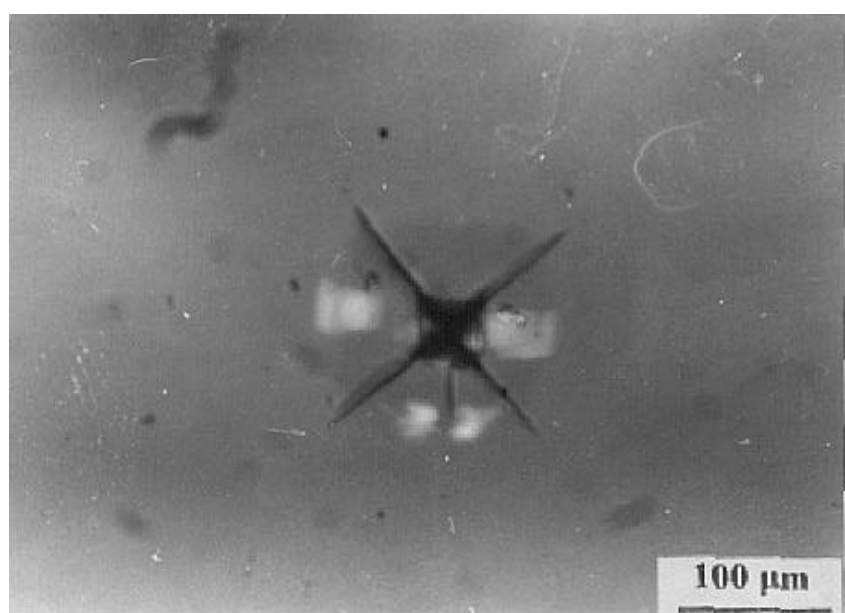

Figure 8. Typical indentation crack pattern in the thin glass disks at a load of $10 \mathrm{~N}$.

failure initiated indeed at centre of the disk, just beneath the zone of maximum tensile stress (DeWith and Wageman 1989). The cracks then moved radially outward. SEM observations made on the fracture surfaces of samples broken in biaxial flexure with three different support ring diameters show features just similar to figure 7 . This is possibly indicative of the involvement of the flaw size distribution with the failure process. If this is the case, the Weibull modulus should not vary appreciably with the variations in the support ring diameter, as has been experimentally observed also (figure 6).

A typical indentation along with the radial cracks obtained at an applied load $(P)$ of $10 \mathrm{~N}$, is shown for the present thin glass disks in figure 8 . It is to be noticed that the subsurface lateral crack formation at such high indentation load is also apparent as white spots in the photomicrograph. It is interesting to note that in spite of having a very small thickness to diameter (T/D) ratio e.g. 0.017, the indentation crack fronts were fairly straight as evidenced by the linear trajectory of the radial cracks. The Vickers microhardness $\left(H_{\mathrm{V}}\right)$ data of the glass disks are presented in figure 9. All the reported data points are an average of at least 15-20 individual indentations. The microhardness data were independent of the indentation loads above $5 \mathrm{~N}$. However, below the indentation load of $5 \mathrm{~N}$, the data showed a somewhat anomalous trend in the sense that apparently the microhardness data increased with indentation load. The reason for this is yet to be known. However, for the load independent range $(5-20 \mathrm{~N})$ the average value of Vickers microhardness was $446 \pm 17.3 \mathrm{kgf} / \mathrm{mm}^{2}$ i.e. about $4.5 \pm 0.17 \mathrm{GPa}$. This is slightly lower than the literature data of $6.6 \mathrm{GPa}$ reported for bulk soda lime silica glass disks (DeWith and Wageman 1989).

The fracture toughness of the glass disks measured at an indentation load of $20 \mathrm{~N}$ was $0.97 \pm 0.08 \mathrm{MPa} \cdot \mathrm{m}^{0.5}$. This data was obtained as an average of at least five to ten

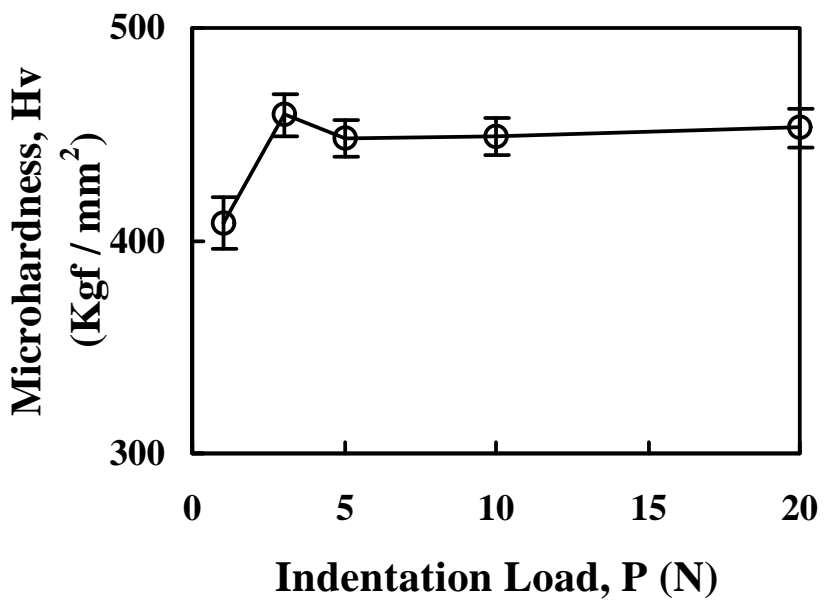

Figure 9. Vicker's microhardness $\left(H_{\mathrm{V}}\right)$ vs indentation load of thin glass disk.

individual indentations. The data obtained for the present thin soda lime silica glass disks thus compare favourably with the $K_{\text {IC }}$ data of $0.72 \mathrm{MPa} \cdot \mathrm{m}^{0.5}$ measured by the double cantilever beam (DCB) technique applied to bulk soda lime silica glass (Mecholsky 1985).

\section{Conclusions}

The major conclusions of the present work are:

(I) The strength $(\sigma)$ of the glass disks measured by biaxial flexure test technique with a ball on ring arrangement was found to be independent of the support ring diameter $(9-17 \mathrm{~mm})$ but decreased very marginally with increasing cross head speed $(0 \cdot 1-10 \mathrm{~mm} / \mathrm{min})$.

(II) The Weibull moduli of the glass disks $(m \approx 3.23 \pm$ $0.44)$ was also insensitive to the variations in the support ring diameter $(\approx 9-17 \mathrm{~mm})$ used in the biaxial flexure test. (III) The Young's modulus $(E)$ of the present glass disks was around $70 \mathrm{GPa}$.

(IV) The Vicker's microhardness $\left(H_{\mathrm{V}}\right)$ was about $4.5 \mathrm{GPa}$ for the applied load range of 5-20 N.

(V) The indentation fracture toughness $\left(K_{\mathrm{IC}}\right)$ of the thin glass disks was $\approx 1 \mathrm{MPa} \cdot \mathrm{m}^{0.5}$.

\section{Acknowledgements}

The financial support received from the Department of Science and Technology (DST), New Delhi, is gratefully acknowledged by one of us (AS). Dr S Mandal and Mrs A Laskar are thanked for the experimental assistance provided in optical microscopy and scanning electron microscopy, respectively. The authors thank Dr H S Maiti for his keen interest and DST for sponsoring the project.

\section{References}

Anstis G R, Chantikul P, Lawn B R and Marshall D B $1981 \mathrm{~J}$. Am. Ceram. Soc. 64533 
DeWith G and Wageman H H M 1989 J. Am. Ceram. Soc. 72 1538

Folsom C A, Zok F W and Lange F F 1994 J. Am. Ceram. Soc. 772081

Hulm B J, Parker J D and Evans W J 1998 J. Mater. Sci. 33 3255

Marshall D B 1980 Am. Ceram. Soc. Bull. 59551

Martin L P and Rosen M 1987 J. Am. Ceram. Soc. 80836
McKiney K R and Herbert C M 1970 J. Am. Ceram. Soc. 53 513

Mecholsky J J 1985 Strength of inorganic glasses (ed) C R Kurjian (New York and London: Plenum Press) p. 569

Shetty D K, Rosenfield A R, Mcguire P, Bansal G K and Duckworth W H 1980 Am. Ceram. Soc. Bull. 591193

Shetty D K, Rosenfield A R, Duckworth W H and Held P R 1983 J. Am. Ceram. Soc. 6636 